\title{
BM] Global Health Associations between social determinants of health and interpersonal violence-related injury in Cameroon: a cross-sectional study
}

\author{
Kevin J Blair (1) , ${ }^{1}$ Michael de Virgilio, ${ }^{1,2}$ Fanny Nadia Dissak-Delon, ${ }^{3}$ \\ Lauren Eyler Dang (DI , ${ }^{4}$ S Ariane Christie, ${ }^{5}$ Melissa Carvalho, ${ }^{1}$ Rasheedat Oke, ${ }^{1}$ \\ Mbiarikai Agbor Mbianyor, ${ }^{1}$ Alan E Hubbard, ${ }^{4}$ Alain Mballa Etoundi, ${ }^{6}$ \\ Thompson Kinge, ${ }^{7}$ Richard L Njock, ${ }^{8}$ Daniel N Nkusu, ${ }^{9}$ Jean-Gustave Tsiagadigui, ${ }^{10}$ \\ Rochelle A Dicker, ${ }^{1}$ Alain Chichom-Mefire (i) , ${ }^{11}$ Catherine Juillard ${ }^{1}$
}

To cite: Blair KJ, de Virgilio M, Dissak-Delon FN, et al. Associations between social determinants of health and interpersonal violence-related injury in Cameroon: a cross-sectional study. BMJ Global Health 2022;7:e007220. doi:10.1136/ bmjgh-2021-007220

Handling editor Seye Abimbola - Additional supplemental material is published online only. To view, please visit the journal online (http://dx.doi.org/10. 1136/bmjgh-2021-007220).

These data were presented at the 5th World Trauma Congress on 15 Feb 2021.

AC-M and CJ are joint senior authors.

Received 17 August 2021 Accepted 7 December 2021

Check for updates

C Author(s) (or their employer(s)) 2022. Re-use permitted under CC BY-NC. No commercial re-use. See rights and permissions. Published by BMJ.

For numbered affiliations see end of article.

Correspondence to

Dr Kevin J Blair;

kevin.james.blair@gmail.com

\section{ABSTRACT}

Introduction Risk factors for interpersonal violencerelated injury (IPVRI) in low-income and middleincome countries (LMICs) remain poorly defined. We describe associations between IPVRI and select social determinants of health (SDH) in Cameroon.

Methods We conducted a cross-sectional analysis of prospective trauma registry data collected from injured patients $\geq 15$ years old between October 2017 and January 2020 at four Cameroonian hospitals. Our primary outcome was IPVRI, compared with unintentional injury. Explanatory SDH variables included education level, employment status, household socioeconomic status (SES) and alcohol use. The EconomicClusters model grouped patients into household SES clusters: rural, urban poor, urban middle-class (MC) homeowners, urban MC tenants and urban wealthy. Results were stratified by sex. Categorical variables were compared via Pearson's $\chi^{2}$ statistic. Associations with IPVRI were estimated using adjusted odds ratios (a0R) with $95 \%$ confidence intervals $(95 \% \mathrm{Cl})$.

Results Among 7605 patients, 5488 (72.2\%) were men. Unemployment was associated with increased odds of IPVRI for men (aOR $2.44(95 \% \mathrm{Cl} 1.95$ to 3.06$)$, $\mathrm{p}<0.001)$ and women (aOR $2.53(95 \% \mathrm{Cl} 1.35$ to 4.72$)$, $\mathrm{p}=0.004)$, as was alcohol use (men: a0R $2.33(95 \%$ Cl 1.91 to 2.83), $p<0.001$; women: aOR $3.71(95 \% \mathrm{Cl}$ 2.41 to 5.72 ), $p<0.001$ ). Male patients from rural (a0R $1.45(95 \% \mathrm{Cl} 1.04$ to 2.03$), p=0.028)$ or urban poor (a0R 2.08 (95\% Cl 1.27 to 3.41), $\mathrm{p}=0.004$ ) compared with urban wealthy households had increased odds of IPVRI, as did female patients with primary-level/ no formal (aOR 1.78 (95\% Cl 1.10 to 2.87), $\mathrm{p}=0.019)$ or secondary-level (aOR 1.54 (95\% Cl 1.03 to 2.32), $\mathrm{p}=0.037$ ) compared with tertiary-level education. Conclusion Lower educational attainment, unemployment, lower household SES and alcohol use are risk factors for IPVRI in Cameroon. Future research should explore LMIC-appropriate interventions to address SDH risk factors for IPVRI.

\section{Key questions}

What is already known?

- Men 15-29 years old have the highest global rate of fatal interpersonal violence-related injury (IPVRI).

- Women bear a significant burden of non-fatal IPVRI but are often under-represented in data due to lowe likelihood of reporting or seeking care for injuries.

- Social determinants of health such as education level, employment status and socioeconomic status (SES) have well-described associations with IPVRI in high-income settings, but data on risk factors for IPVRI in low-income and middle-income countries (LMICs) are limited.

What are the new findings?

- Among both male and female injured patients who sought hospital-level care in Cameroon, unemployment and alcohol use were associated with greate odds of IPVRI compared with unintentional injury.

- Female patients with primary-level/no formal or secondary-level education had greater odds of IPVR compared with those with university-level education.

- Male patients from rural or urban poor household SES clusters had greater odds of IPVRI compared with those from the urban wealthy cluster.

\section{INTRODUCTION}

Interpersonal violence-related injury (IPVRI) remains a leading cause of global injury and death. ${ }^{1-3}$ The WHO defines interpersonal violence as 'the intentional use of physical force or power, threatened or actual, against...another person, or against a group or community, that either results in or has a high likelihood of resulting in injury, death, psychological harm, maldevelopment or deprivation. ${ }^{2} 3$ Such a broad definition encompasses both family-inflicted or partnerinflicted violence, which are more common 


\section{Key questions}

What do the new findings imply?

- Policy-level and individual-level interventions to address low educational attainment, chronic unemployment, poverty and harmful alcohol use in sub-Saharan Africa may be areas of investment to reduce IPVRI.

- The hospital setting could be used to connect victims of IPVRI with resources to address risk factors identified in this study, such as low educational attainment, unemployment and harmful alcohol use, though feasibility of hospital-based violence intervention programmes has yet to be demonstrated in an LMIC setting.

- More data are needed to characterise risk factors for IPVRI among the rural Cameroonian population and among women who do not seek hospital-level care for their injuries.

among women, as well as community-based violence inflicted by acquaintances or strangers, which is more common among men. ${ }^{3-5}$ Men represented more than $80 \%$ of the estimated 415000 deaths due to IPVRI in $2019,{ }^{6}$ but women and girls are known to bear a significant burden of non-fatal IPVRI and may be underrepresented in data due to lower likelihood of reporting or seeking care for their injuries. ${ }^{2}$

Prevention of IPVRI is a key global public health priority of the $\mathrm{WHO},{ }^{3}{ }^{7-10}$ and a public health approach to the prevention of IPVRI involves identifying risk and protective factors and developing targeted interventions. ${ }^{4}$ An ecological model of understanding IPVRI suggests that there is not one factor to explain risk of or protection from IPVRI, but rather a complex set of inter-related societal, community, relationship and individual factors. ${ }^{3}$ Younger age is a well-known risk factor for IPVRI, with the 15-29 years old age group having the highest global male and female homicide rate. ${ }^{2}$ Other risk factors for IPVRI are known as social determinants of health $(\mathrm{SDH})$, which are defined by the WHO as non-medical factors that influence a variety of health conditions. ${ }^{11} \mathrm{SDH}$ include employment, educational attainment and socioeconomic status (SES), among many others. ${ }^{11}{ }^{12}$ While not an SDH itself, alcohol use is also a risk factor for IPVRI ${ }^{313}$ and is associated with SDH such as education and SES. ${ }^{14}$

Much of the violence prevention research over the past two decades has come from high-income countries (HICs), despite the fact that approximately $90 \%$ of deaths from IPVRI occur in low-income and middleincome countries (LMICs). ${ }^{121516}$ This is due in part to limited availability of reliable injury data in many LMICs. In Africa, for example, an estimated $70 \%$ of countries lack access to vital or civil registration homicide data, which greatly impedes research on the burden of IPVRI and its associated risk factors. ${ }^{2}$ To fill this gap, recent research has used hospital-level ${ }^{17-28}$ or demographic survey ${ }^{29-34}$ data to better characterise the burden of IPVRI in sub-Saharan Africa. There remains a need for further research on IPVRI, though, as many of these studies have been limited by small sample size, a broad definition of interpersonal violence, lack of focus on risk and protective factors or absence of a control group.

The Republic of Cameroon (Cameroon) is a lowermiddle income country located in sub-Saharan Africa with an estimated population of 28.5 million in $2021 .^{35} \mathrm{In}$ response to the need to better characterise the burden of injury in the country, the Cameroon National Trauma Registry project was implemented in 2015 and collects data from all injured patients who receive care at one of the four pilot trauma registry hospitals. ${ }^{36}{ }^{37}$ Early trauma registry data from Cameroon demonstrated a number of demographic and socioeconomic correlates of injury, ${ }^{38-40}$ and a resultant aim of the pilot trauma registry project was to identify and address inequities in the burden of injury in the country. To that end, we used data collected as a part of the Cameroon National Trauma Registry project to explore associations between IPVRI and education level, employment status, household SES cluster and alcohol use among a cross-sectional sample of injured patients seeking hospital-level care in Cameroon.

\section{METHODS}

\section{Study design, setting and population}

We conducted a cross-sectional analysis of prospective trauma registry cohort data collected between October 2017 and January 2020 in Cameroon. The Cameroon National Trauma Registry project collects data from injured patients presenting to the following four hospitals located in the Southwest region of Cameroon: Laquintinie Hospital of Douala is a tertiary-level public hospital located in Douala, which is the most populous city in Cameroon; Limbe Regional Hospital is a regional hospital located in the city of Limbe; Edea Regional Hospital is a smaller regional hospital located in the city of Edea; and Catholic Hospital Pouma is a faith-based district hospital located along the main roadway between Douala and Yaounde known for frequent motor vehicle collisions.

Trauma registry data are prospectively collected at each facility using an established trauma registry data collection form (online supplemental document), which is filled out by research assistants trained in human subjects research (see Ethical Considerations) or by state registered nurses under the supervision of the research assistants. Data are collected directly from the patient, guardian (for minors $<18$ years old) and/or surrogate via faceto-face interview, as well as from the treating physician and medical record. For patients too severely injured to respond or for those who have died, family or surrogates are interviewed when available. Private interviews take place either in a consultation room or at the patient's bedside in the emergency unit. Individuals accompanying a patient may be asked to leave during the interview on a case-by-case basis. Data from trauma registry forms completed between 2017 and 2020 were compiled using the REDCap (Research Electronic Data Capture) 
tools hosted at University of California, San Francisco (UCSF). ${ }^{41} 42$

This analysis includes injured patients $\geq 15$ years old. Patients who were missing sex, age, hospital or injury details were excluded, as were those who were missing intention of injury and those who were missing data for all three SDH explanatory variables (education level, employment status and household SES cluster). Lastly, given our focus on IPVRI, we excluded patients with injuries from self-harm or suicide. Of note, injured patients who died were included in this analysis as long as they were not missing data as described above.

\section{Variables}

Outcome

Our primary outcome was IPVRI, which was defined as intentional injury or death due to assault, homicide or legal intervention. Legal intervention refers to injuries sustained during an encounter with law enforcement. Patients with IPVRI were compared with those who sustained unintentional injuries, the most common of which were road traffic injuries (RTIs) or falls. Use of unintentionally injured persons as controls, rather than uninjured persons, has been employed by similar studies in the region ${ }^{17}$ and will likely result in conservative estimates of associations with SDH risk factors, since unintentional injuries such as RTIs are also known to be associated with many $\mathrm{SDH} .{ }^{31} 43$

\section{Sex and age}

Sex was collected as male or female. Given differences in the epidemiology of and risk factors for IPVRI among men and women, ${ }^{2}$ all results in this analysis are stratified by sex. Age was collected as a continuous variable and subsequently categorised as $15-24,25-34,35-44,45-54$ and 55 +years old for analysis.

\section{Injury characteristics}

Data were collected on injury mechanism, perpetrator (specific to IPVRI) and location, as well as mode of transport to the hospital. Injury severity was classified using the Injury Severity Score (ISS). ${ }^{44}$ Disposition from the emergency department (ED) was grouped as 'discharged home,' 'admitted to hospital,' 'transferred,' 'left against medical advice' or 'died.' Overall hospital mortality includes deaths recorded in the ED as well as deaths during hospital admission.

\section{Explanatory variables}

Education level was collected as 'no formal,' 'primary,' 'secondary/high school' or 'tertiary/college.' We refer to the 'tertiary/college' category as 'university-level.' A patient was categorised as achieving a certain level of schooling if they had completed any years of that level. For analysis, 'no formal' and 'primary' were grouped.

Employment status was collected according to the following categories: 'self-employed,' 'salaried,' 'student,' 'housewife,' 'unemployed (able to work),' 'unemployed (unable to work),' 'retired,' 'unknown' or 'other.' Of note, 'student' includes both current students and those working in unpaid apprenticeships, and 'housewife' is specific to women and refers to those who are married and take care of the home and/or children but are not seeking formal employment. For analysis, 'selfemployed,' 'salaried' and all applicable free responses to 'other' were grouped as 'employed' and 'unemployed (able to work)' and 'unemployed (unable to work)' were grouped as 'unemployed.' Given the small sample of women who identified as 'retired,' we combined 'housewife' and 'retired' for analysis.

Household SES cluster was determined according to a previously-developed Cameroon-specific EconomicClusters model, which consists of six economic groups: rural poor, rural wealthy, urban poor, urban middle-class (MC) homeowners, urban MC tenants and urban wealthy. ${ }^{45} 46$ Briefly, individual patients provided information about their household via the following five items, which were selected by the EconomicClusters algorithm as the Demographic and Health Survey (DHS) assets that define the most distinct economic groups in the Cameroonian population: urban or rural location; own, rent or live for free in home; cellphone ownership; agricultural land ownership; and type of cooking fuel used. ${ }^{45} 46$ If an individual listed more than one cooking fuel, we used the highestcost cooking fuel. Patients were then assigned to the SES cluster that included members of the Cameroonian DHS population with the same asset profile, based on the original EconomicClusters model. Due to the small sample of patients from rural poor households seeking hospitallevel care in this sample, we combined the rural poor and rural wealthy household SES clusters for analysis.

Alcohol use was assessed via the question, 'Did alcohol likely contribute to this injury?' Response options included 'yes', 'no' and 'unknown.' The question primarily refers to alcohol consumption by the patient as determined by the patient's history, physical examination and/or laboratory test results. In rare cases for which there was evidence, a 'yes' response may have been recorded in reference to another individual involved in the injury.

\section{Statistical analysis}

Data were exported from REDCap and analysed using Stata/IC V.16.1. ${ }^{47}$ All results were stratified by sex. Categorical and continuous variables were compared using Pearson's $\chi^{2}$ statistic and Wilcoxon rank-sum, respectively. Our outcome of IPVRI was compared with unintentional injury. Multivariable regression models adjusted for age and hospital estimated adjusted odds ratios (aOR) with $95 \%$ confidence intervals (95\% CI) for education level, employment status, household SES cluster and alcohol use. We include missing education, employment and household SES cluster data as dummy variable categories in our regression models, since models with dummy categories were found to have equivalent results to models which dropped patients with missing data. Unadjusted and full adjusted models are presented below 
and expanded tables including the stepwise addition of explanatory variables are available as online supplemental tables.

\section{Ethical considerations}

The research assistants who oversee data collection have completed Collaborative Institutional Training Initiative programme courses in human subjects research and have signed the UCSF Statement of Responsibility for the Request of Personally Identifiable Information and/or Protected Health Information (2016) and the University of California, Los Angeles Confidentiality Agreement (2019). Completed courses on the ethics of human subjects research, however, were not specific to the safety and ethics of gathering information about sexual assault, violence against women or intimate partner violence as outlined by the $\mathrm{WHO}^{48}$

Patients and/or surrogates provided oral consent for research, and those without consent are excluded from this analysis. During the oral consent process, research assistants provide assurances that responses will remain confidential and that the trauma registry form is stored in a locked room in the hospital only accessible to the medical team and research staff.

\section{RESULTS}

A total of 9625 injured patients were included in the trauma registry between October 2017 and January 2020. After exclusions, 7605 were included in this analysis (figure 1), $5488(72.2 \%)$ of whom were men. Characteristics of excluded patients are presented in online supplemental table S1. Among included patients, $18.0 \%$ $(\mathrm{n}=1336)$ presented after IPVRI and $82.0 \% \quad(\mathrm{n}=6239)$ after unintentional injury. The proportion of IPVRI was higher among men compared with women $(19.7 \%$ vs $14.7 \%, \mathrm{p}<0.001)$, and the age group comprising 15-34year-olds accounted for a larger percentage of those with IPVRI compared with unintentional injury for both men $(67.1 \%$ vs $57.8 \%, \mathrm{p}<0.001)$ and women $(65.7 \%$ vs $51.0 \%, \mathrm{p}<0.001$ ) (figure 2 ).

\section{Injury characteristics}

IPVRIs were most commonly a result of being struck by a person or object (men: $52.6 \%$; women: $80.7 \%$ ), followed by stab or cut (men: $36.1 \%$; women: $8.8 \%$ ) (table 1 ). Conversely, the most common mechanism of unintentional injury was RTI (men: $75.8 \%$; women: $71.3 \%$ ) followed by fall (men: 10.8\%; women: 16.3\%). Among male patients, the perpetrator of IPVRI was a mix between friend or acquaintance $(30.7 \%)$, stranger $(30.6 \%)$ or unknown $(30.7 \%)$ and the most common location of injury was road or highway $(44.0 \%)$. Conversely, female patients with IPVRI were most commonly injured by a partner or ex-partner $(40.2 \%)$ or friend or acquaintance $(29.8 \%)$, and a majority of IPVRIs among women occurred at home or a private residence $(55.2 \%)$. Median ISS was similar between the IPVRI and unintentional injury groups for men ( 9 vs $8, \mathrm{p}=0.966$ ), but was lower

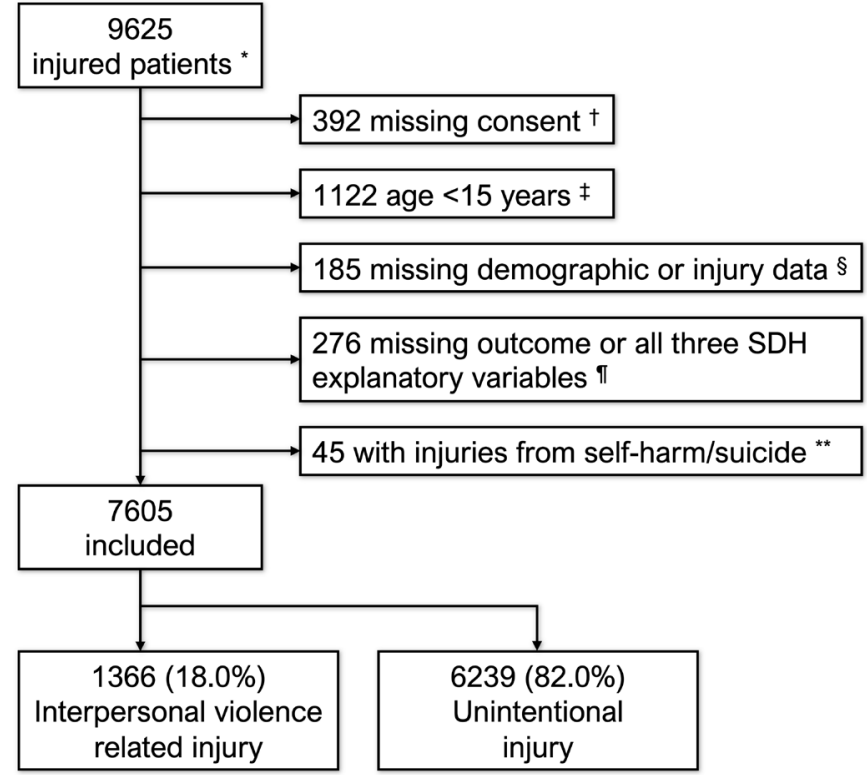

Figure 1 Flow diagram of injured patients who sought hospital-level care in Cameroon between October 2017 and January 2020 and were included in the present analysis. * Injured patients presenting to one of the four Cameroon trauma registry hospitals. ${ }^{\dagger} A$ similar percentage of men (3.8\%) and women (3.7\%) were missing consent. ${ }^{\ddagger}$ Of the children excluded from this analysis, $n=647(57.7 \%)$ were male, $n=472(42.1 \%)$ were female and $n=3(0.3 \%)$ were missing sex data. There were 51 (4.5\%) with IPVRI, with a slightly higher percentage of IPVRI among women (5.6\%) than men (4.3\%). ${ }^{\S}$ Includes 36 who were missing age, sex and/or hospital, 127 who were either uninjured or missing injury data, and 10 with internal data inconsistencies.

ISee online supplemental table S1 for demographic and injury characteristics of patients excluded due to missing intention of injury $(n=232)$ or for missing education, employment and household SES cluster data $(n=44)$. ** Most self-inflicted injuries were among women ( $n=31,68.9 \%)$. IPVRI, interpersonal violence-related injury; SDH, social determinants of health; SES, socioeconomic status.

among women with IPVRI compared with unintentional injury ( 3 vs $5, \mathrm{p}<0.001$ ). After receiving care for their injuries, those with IPVRI were more likely to be discharged home (men: $73.6 \%$ vs $54.4 \%$, p $<0.001$; women: $86.9 \%$ vs $67.5 \%, \mathrm{p}<0.001$ ) compared with those with unintentional injuries. Overall hospital mortality was not significantly different between injury groups for either men $(2.3 \%$ vs $2.3 \%, \mathrm{p}=0.882)$ or women $(0.3 \%$ vs $1.7 \%, \mathrm{p}=0.074)$.

\section{Explanatory variables and IPVRI}

Patients with IPVRI were more likely to have primarylevel education (men: $27.0 \%$ vs $24.4 \%$; women: $23.5 \%$ vs $19.6 \%)$ and less likely to have university-level education (men: $8.5 \%$ vs $11.5 \%, \mathrm{p}<0.001$; women: $13.1 \%$ vs $17.9 \%, p=0.153)$ when compared with those with unintentional injuries (table 2). Most patients reported some form of employment (70.4\%), though employment was significantly higher among male $(76.1 \%)$ compared with female patients $(51.8 \%, \mathrm{p}<0.001)$ due to the large number of women who reported being a housewife 

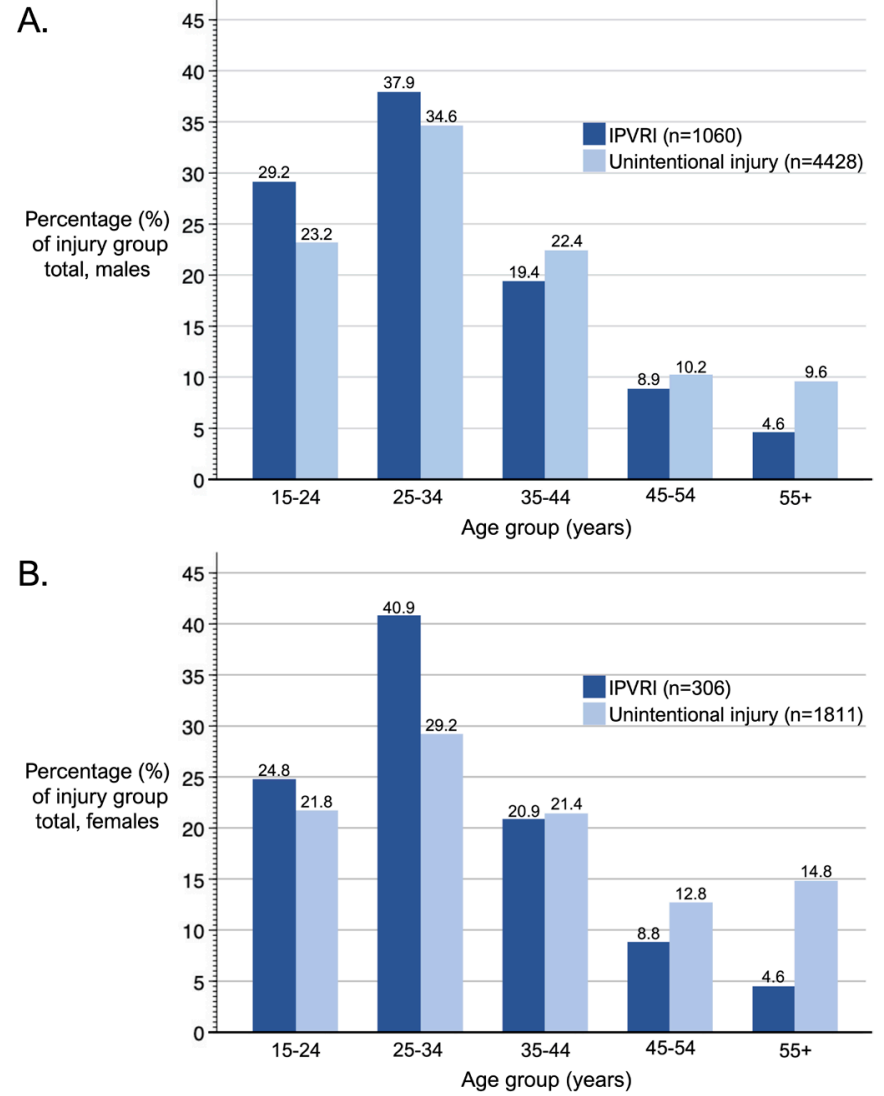

Figure 2 Age group distribution of men (A) and women (B) who sought hospital-level care for interpersonal violencerelated injuries or unintentional injuries in Cameroon between 2017 and 2020. IPVRI, interpersonal violence-related injury.

$(n=531,25.1 \%)$. Patients with IPVRI had higher levels of unemployment (men: $15.9 \%$ vs $5.9 \%, \mathrm{p}<0.001$; women: $5.9 \%$ vs $2.2 \%, \mathrm{p}=0.001)$ compared with those with unintentional injuries. Male patients presenting after IPVRI were more likely to be classified into the urban poor (3.5\% vs $1.2 \%$ ), urban MC homeowner (13.7\% vs $12.7 \%$ ) and urban MC tenant (58.2\% vs $54.4 \%$ ) household SES clusters, and less likely to be classified as urban wealthy (13.5\% vs $18.1 \%, \mathrm{p}<0.001)$. Likewise, female patients with IPVRI were more likely to be classified into the rural ( $10.4 \%$ vs $8.2 \%)$, urban poor $(1.7 \%$ vs $0.8 \%)$ and urban MC tenant (55.9\% vs $51.8 \%$ ) household SES clusters, and less likely to be classified as urban wealthy $(19.9 \%$ vs $25.6 \%, \mathrm{p}=0.202)$. Alcohol use was greater in both male (19.8\% vs $11.1 \%, \mathrm{p}<0.001)$ and female $(13.7 \%$ vs $4.1 \%$, $\mathrm{p}<0.001)$ patients with IPVRI compared with unintentional injuries.

\section{Adjusted associations with IPVRI}

Compared with university-level education, women who had a primary-level/no formal (aOR 1.78 (95\% CI 1.10 to 2.87 ), $\mathrm{p}=0.019$ ) or secondary-level (aOR 1.54 (95\% CI 1.03 to 2.32 ), $\mathrm{p}=0.037$ ) education had significantly increased odds of IPVRI (table 3). The association between education and IPVRI among men lost significance when adjusted for age and hospital (online supplemental table S2). Being unemployed compared with employed was associated with significantly increased odds of IPVRI in both men (aOR 2.44 (95\% CI 1.95 to 3.06), $\mathrm{p}<0.001$ ) and women (aOR 2.53 (95\% CI 1.35 to 4.72), $\mathrm{p}=0.004)$. Among male patients, being from a rural household (aOR 1.45 (95\% CI 1.04 to 2.03), $\mathrm{p}=0.028$ ) or an urban poor household (aOR 2.08 (95\% CI 1.27 to 3.41), $\mathrm{p}=0.004$ ) were both associated with increased odds of IPVRI when compared with the urban wealthy household SES cluster. Similar unadjusted associations were seen among female patients from rural (OR $1.63(95 \%$ CI 1.02 to 2.60), $\mathrm{p}=0.040$ ) or urban poor households (OR 2.53 (95\% CI 0.89 to 7.21), p=0.082), though the association for rural households lost significance when all four explanatory variables were included in the model (online supplemental table S3). Alcohol use was significantly associated with IPVRI for both men (aOR $2.33(95 \%$ CI 1.91 to 2.83$), \mathrm{p}<0.001)$ and women (aOR 3.71 (95\% CI 2.41 to 5.72$), \mathrm{p}<0.001)$.

\section{DISCUSSION}

These findings provide strong evidence of an association between IPVRI and education level, employment status, household SES cluster and alcohol use among a crosssectional sample of injured patients who sought hospitallevel care in Cameroon. While these associations have been previously described as targets for global violence prevention efforts, supporting data from countries in sub-Saharan Africa have been scarce. This study thus serves as an important contribution to the limited body of research on risk and protective factors for IPVRI in these settings. Moreover, our results, which are suggestive of a protective effect of higher education, employment, higher household SES and limiting alcohol misuse, could aid in identifying interventions to prevent IPVRI in Cameroon and other sub-Saharan Africa countries.

We found lower educational attainment to be associated with IPVRI in adjusted analyses for female patients, but not for male patients. A similar trend was seen in the 2018 DHS data for Cameroon, which showed the percentage of women who had experienced physical violence in the previous year was $22.3 \%$ in those with primary-level education and $8.2 \%$ in those with universitylevel education. Previous studies from sub-Saharan Africa have shown women with lower educational attainment have higher risk of intimate partner violence, ${ }^{40} 50$ though our study was not designed to explore risk of intimate partner violence specifically. Among men, the association between education and IPVRI lost significance in the adjusted regression models, highlighting the relatedness of these explanatory variables and the importance of accounting for confounders when evaluating $\mathrm{SDH}$ as risk factors for health outcomes in the region. Among other research exploring education and IPVRI, studies from Tanzania, ${ }^{51}$ Kenya $^{31}$ and Latin America ${ }^{52}$ all have findings suggestive of a protective effect of higher educational attainment. 
Table 1 Characteristics of interpersonal violence-related injuries compared with unintentional injuries among Cameroonian patients $\geq 15$ years old who sought hospital-level care between 2017 and 2020, stratified by sex

\begin{tabular}{|c|c|c|c|c|c|c|c|}
\hline \multirow[b]{2}{*}{ Variable } & \multirow[b]{2}{*}{$\begin{array}{l}\text { Overall } \\
\mathrm{N}=7605\end{array}$} & \multicolumn{3}{|c|}{ Males, $n=5488$} & \multicolumn{3}{|c|}{ Females, $n=2117$} \\
\hline & & $\begin{array}{l}\text { IPVRI } \\
n=1060\end{array}$ & $\begin{array}{l}\text { Unintentional } \\
n=4428\end{array}$ & $P$ value & $\begin{array}{l}\text { IPVRI } \\
\mathrm{n}=306\end{array}$ & $\begin{array}{l}\text { Unintentional } \\
n=1811\end{array}$ & $P$ value \\
\hline Hospital, n (\%) & & & & $<0.001^{*}$ & & & $0.014^{*}$ \\
\hline LHD & 3250 (42.7) & 659 (62.2) & 1841 (41.6) & & $97(31.7)$ & $653(36.0)$ & \\
\hline LRH & $2866(37.7)$ & 278 (26.2) & 1633 (36.9) & & $153(50.0)$ & $802(44.3)$ & \\
\hline $\mathrm{ERH}$ & 1061 (14.0) & 108 (10.2) & $646(14.6)$ & & 50 (16.3) & 257 (14.2) & \\
\hline $\mathrm{CHP}$ & $428(5.6)$ & $15(1.4)$ & $308(6.9)$ & & $6(2.0)$ & $99(5.5)$ & \\
\hline Mechanism, n (\%) & & & & $<0.001^{*}$ & & & $<0.001^{*}$ \\
\hline Road traffic injury & 4656 (61.2) & $5(0.5)$ & 3357 (75.8) & & $3(1.0)$ & 1291 (71.3) & \\
\hline $\begin{array}{l}\text { Struck by } \\
\text { person, animal, } \\
\text { object }\end{array}$ & $1073(14.1)$ & $558(52.6)$ & $202(4.6)$ & & $247(80.7)$ & $66(3.6)$ & \\
\hline Fall & $799(10.5)$ & $17(1.6)$ & $478(10.8)$ & & $9(2.9)$ & $295(16.3)$ & \\
\hline Stab or cut & $649(8.6)$ & $383(36.1)$ & $183(4.1)$ & & $27(8.8)$ & $56(3.1)$ & \\
\hline Firearm & $78(1.0)$ & $62(5.9)$ & $10(0.2)$ & & $4(1.3)$ & $2(0.1)$ & \\
\hline Other $†$ & $319(4.2)$ & $26(2.4)$ & $183(4.1)$ & & $14(4.6)$ & $96(5.3)$ & \\
\hline Missing data & $31(0.4)$ & $9(0.9)$ & $15(0.4)$ & & $2(0.7)$ & $5(0.3)$ & \\
\hline \multicolumn{8}{|l|}{ Perpetrator, n (\%) ‡ } \\
\hline $\begin{array}{l}\text { Friend or } \\
\text { acquaintance }\end{array}$ & $416(30.5)$ & $325(30.7)$ & - & & $91(29.8)$ & - & \\
\hline Stranger $\S$ & $369(27.0)$ & $324(30.6)$ & - & & $45(14.7)$ & - & \\
\hline $\begin{array}{l}\text { Partner or ex- } \\
\text { partner }\end{array}$ & $152(11.1)$ & $29(2.7)$ & - & & $123(40.2)$ & - & \\
\hline $\begin{array}{l}\text { Parent, guardian, } \\
\text { or other relative }\end{array}$ & $43(3.1)$ & $24(2.2)$ & - & & $19(6.2)$ & - & \\
\hline Police & $34(2.5)$ & $33(3.1)$ & - & & $1(0.3)$ & - & \\
\hline Unknown & 352 (25.8) & $325(30.7)$ & - & & $27(8.8)$ & - & \\
\hline Location, n (\%) & & & & $<0.001^{*}$ & & & $<0.001^{*}$ \\
\hline Road or highway & $5311(69.8)$ & $466(44.0)$ & 3453 (78.0) & & $48(15.7)$ & 1344 (74.2) & \\
\hline $\begin{array}{l}\text { Home or private } \\
\text { residence }\end{array}$ & 977 (12.9) & $152(14.3)$ & 317 (7.2) & & 169 (55.2) & 339 (18.7) & \\
\hline $\begin{array}{l}\text { Trade, service, or } \\
\text { construction area }\end{array}$ & $459(6.0)$ & $170(16.0)$ & $225(5.1)$ & & $36(11.8)$ & $28(1.5)$ & \\
\hline Public area & $301(4.0)$ & $180(17.0)$ & $64(1.4)$ & & $38(12.4)$ & $19(1.1)$ & \\
\hline Farm & $228(3.0)$ & $13(1.2)$ & $181(4.1)$ & & $2(0.7)$ & $32(1.8)$ & \\
\hline Other & $293(3.8)$ & $62(5.9)$ & $181(4.1)$ & & $12(3.9)$ & $38(2.1)$ & \\
\hline Missing data & $36(0.5)$ & $17(1.6)$ & $7(0.1)$ & & $1(0.3)$ & $11(0.6)$ & \\
\hline \multicolumn{4}{|c|}{ Transport to hospital, n (\%) } & $<0.001^{*}$ & & & $<0.001^{*}$ \\
\hline Taxi & $3800(50.0)$ & $491(46.3)$ & $2225(50.3)$ & & $149(48.7)$ & 935 (51.6) & \\
\hline Motorcycle & 1924 (25.3) & $316(29.8)$ & 1055 (23.8) & & $115(37.6)$ & $438(24.2)$ & \\
\hline Private vehicle & 1007 (13.2) & $57(5.4)$ & $677(15.3)$ & & $20(6.5)$ & $253(14.0)$ & \\
\hline $\begin{array}{l}\text { Police or } \\
\text { firefighters }\end{array}$ & $209(2.7)$ & $131(12.4)$ & $58(1.3)$ & & $3(1.0)$ & $17(0.9)$ & \\
\hline Ambulance & $128(1.7)$ & $11(1.0)$ & $82(1.9)$ & & $1(0.3)$ & $34(1.9)$ & \\
\hline Other & $410(5.4)$ & $36(3.4)$ & 263 (5.9) & & $12(3.9)$ & $99(5.5)$ & \\
\hline Missing data & $127(1.7)$ & $18(1.7)$ & $68(1.5)$ & & $6(2.0)$ & $35(1.9)$ & \\
\hline
\end{tabular}

Continued 


\begin{tabular}{|c|c|c|c|c|c|c|c|}
\hline \multirow[b]{2}{*}{ Variable } & \multirow[b]{2}{*}{$\begin{array}{l}\text { Overall } \\
N=7605\end{array}$} & \multicolumn{3}{|c|}{ Males, $n=5488$} & \multicolumn{3}{|c|}{ Females, $\mathrm{n}=2117$} \\
\hline & & $\begin{array}{l}\text { IPVRI } \\
n=1060\end{array}$ & $\begin{array}{l}\text { Unintentional } \\
\mathrm{n}=4428\end{array}$ & $P$ value & $\begin{array}{l}\text { IPVRI } \\
n=306\end{array}$ & $\begin{array}{l}\text { Unintentional } \\
n=1811\end{array}$ & P value \\
\hline \multicolumn{2}{|l|}{ Injury severity scoreף } & & & 0.966 & & & $<0.001^{*}$ \\
\hline Median (IQR) & $8(2-13)$ & $9(4-13)$ & $8(2-13)$ & & $3(1-8)$ & $5(1-12)$ & \\
\hline \multicolumn{2}{|c|}{ Disposition from ED, $\mathrm{n}(\%)$} & & & $<0.001^{*}$ & & & $<0.001^{*}$ \\
\hline \multicolumn{2}{|c|}{ Discharged home 4679 (61.5) } & $780(73.6)$ & $2410(54.4)$ & & $266(86.9)$ & $1223(67.5)$ & \\
\hline $\begin{array}{l}\text { Admitted to } \\
\text { hospital }\end{array}$ & $1195(15.7)$ & $96(9.1)$ & $822(18.6)$ & & $18(5.9)$ & $259(14.3)$ & \\
\hline Transferred & $380(5.0)$ & $52(4.9)$ & $254(5.7)$ & & $1(0.3)$ & $73(4.0)$ & \\
\hline $\begin{array}{l}\text { Left against } \\
\text { medical advice }\end{array}$ & $1114(14.7)$ & $81(7.6)$ & $796(18.0)$ & & $17(5.6)$ & $220(12.2)$ & \\
\hline Died & $127(1.7)$ & $21(2.0)$ & $80(1.8)$ & & $1(0.3)$ & $25(1.4)$ & \\
\hline Missing data & $110(1.4)$ & $30(2.8)$ & $66(1.5)$ & & $3(1.0)$ & $11(0.6)$ & \\
\hline \multicolumn{2}{|c|}{ Overall hospital mortality, n (\%) ** } & & & 0.882 & & & 0.074 \\
\hline Died & $153(2.0)$ & $24(2.3)$ & 98 (2.3) & & $1(0.3)$ & $30(1.7)$ & \\
\hline
\end{tabular}

*Significant at the $p<0.05$ level.

†Includes animal bite, drowning/submersion, burn, scald, poisoning, suffocation/choking/hanging, electrocution, explosive blast, envenomation or other.

‡Only applies to the 1366 patients with IPVRI.

§Among those injured by strangers, 79 male patients were suspected to have been injured in a situation of 'popular justice,' in which witnesses of an alleged crime beat the perpetrator as punishment.

IInjury severity score ranges from 1 to 75 , with higher scores indicating more severe injury.

${ }^{*}$ Overall hospital mortality includes deaths recorded in the ED and deaths which occurred during hospital admission. Of note, there were 150 patients (125 men, 25 women) who were missing overall hospital mortality data.

CHP, Catholic Hospital Pouma; ED, emergency department; ERH, Edea Regional Hospital ; IPVRI, interpersonal violence-related injury; LHD, Laquintinie Hospital of Douala ; LRH, Limbe Regional Hospital .

Both men and women in our study who reported being unemployed had significantly increased risk of IPVRI. Similar findings were demonstrated in a study using hospital-based trauma registry data from Malawi ${ }^{17}$ and another using police homicide data in Tanzania. ${ }^{51}$ Relatedly, a South African study using household survey data demonstrated that employment of the head of household, rather than the individual, was associated with decreased risk of death due to IPVRI. ${ }^{29}$ While our data provide strong evidence to suggest that employment may be protective against IPVRI, our study was not designed to assess the risk or protective effect associated with specific types of jobs common to Cameroon. According to the 2018 DHS report for Cameroon, the most common occupation categories for men aged 15-49 were farmer or agricultural worker $(38 \%)$, sales or service personnel $(27 \%)$ and skilled manual labour $(24 \%)$ and the most common occupations for women were sales or service personnel $(44 \%)$ and farmer or agricultural worker $(44 \%) .{ }^{34}$ Now that we have identified strong associations between employment and IPVRI, future research should build on our findings to explore associations with these specific types of jobs common among men and women in Cameroon.

Ours is the first study to explore associations between SES and IPVRI in sub-Saharan Africa using a recently developed EconomicClusters model. ${ }^{45}$ 46 A number of studies exploring SES in the household survey setting have used wealth index models, ${ }^{29} 303254$ but collecting data for the many asset variable components of the wealth index is time consuming and often infeasible in an emergency healthcare setting. ${ }^{45}$ Other studies have evaluated household monthly income, ${ }^{19} 202223$ but monthly income is known to be an inadequate correlate of SES in sub-Saharan Africa due to the importance of nonmonetary resources in many communities.$^{55}$ Employment and education level can also be used as proxies, but are also inadequate at fully capturing socioeconomic position. ${ }^{1255} 56$ The EconomicClusters model ${ }^{45}{ }^{46}$ in contrast, is more context-appropriate than income and requires data collection on fewer variables, which is more feasible for a trauma registry. ${ }^{45}$

We found that compared with those in the urban wealthy household SES cluster, male patients from the combined rural and the urban poor clusters had increased odds of IPVRI, even when controlling for education and employment. Weaker associations were seen among female patients, likely due to smaller sample size. These findings are consistent with the original validation of the EconomicClusters model, which found that rural poor, rural wealthy and urban poor SES clusters had lower child heightfor-age Z-scores, lower women's literacy and higher child mortality than the urban MC homeowner, urban MC 
Table 2 Sociodemographic characteristics of Cameroonian patients $\geq 15$ years old who sought hospital-level care for interpersonal violence-related injury compared with unintentional injury between 2017 and 2020, stratified by sex

\begin{tabular}{|c|c|c|c|c|c|c|c|}
\hline \multirow[b]{2}{*}{ Variable } & \multirow[b]{2}{*}{$\begin{array}{l}\text { Overall, } \\
\mathrm{N}=7605\end{array}$} & \multicolumn{3}{|c|}{ Males, $\mathrm{n}=5488$} & \multicolumn{3}{|c|}{ Females, $n=2117$} \\
\hline & & $\begin{array}{l}\text { IPVRI } \\
n=1060\end{array}$ & $\begin{array}{l}\text { Unintentional } \\
\mathrm{n}=4428\end{array}$ & $P$ value & $\begin{array}{l}\text { IPVRI } \\
\mathrm{n}=306\end{array}$ & $\begin{array}{l}\text { Unintentional } \\
n=1811\end{array}$ & $P$ value \\
\hline \multicolumn{8}{|l|}{ Age, $n(\%)$} \\
\hline Median (IQR) & $32(25-42)$ & $29(23.5-38)$ & $32(25-41)$ & $<0.001^{*}$ & $30(25-38)$ & $34(26-46)$ & $<0.001^{*}$ \\
\hline $15-24$ & $1805(23.7)$ & $309(29.2)$ & $1026(23.2)$ & $<0.001^{*}$ & $76(24.8)$ & $394(21.8)$ & $<0.001^{*}$ \\
\hline $25-34$ & $2590(34.1)$ & $402(37.9)$ & $1534(34.6)$ & & $125(40.9)$ & $529(29.2)$ & \\
\hline $35-44$ & $1649(21.7)$ & $206(19.4)$ & $991(22.4)$ & & $64(20.9)$ & $388(21.4)$ & \\
\hline $45-54$ & $805(10.6)$ & $94(8.9)$ & $453(10.2)$ & & $27(8.8)$ & $231(12.8)$ & \\
\hline $55+$ & $756(9.9)$ & $49(4.6)$ & $424(9.6)$ & & $14(4.6)$ & $269(14.8)$ & \\
\hline \multicolumn{2}{|c|}{ Education level, n (\%) } & & & $<0.001^{*}$ & & & 0.153 \\
\hline No formal $\dagger$ & $402(5.3)$ & $82(7.7)$ & $207(4.7)$ & & $13(4.2)$ & $100(5.5)$ & \\
\hline Primary† & $1793(23.6)$ & $286(27.0)$ & $1081(24.4)$ & & $72(23.5)$ & $354(19.6)$ & \\
\hline $\begin{array}{l}\text { Secondary/high } \\
\text { school }\end{array}$ & $3868(50.8)$ & $517(48.8)$ & $2308(52.1)$ & & $155(50.7)$ & $888(49.0)$ & \\
\hline University & $966(12.7)$ & $90(8.5)$ & $511(11.5)$ & & $40(13.1)$ & 325 (17.9) & \\
\hline Missing data & $576(7.6)$ & $85(8.0)$ & $321(7.3)$ & & $26(8.5)$ & $144(8.0)$ & \\
\hline \multicolumn{2}{|c|}{ Employment status, n (\%) } & & & $<0.001^{*}$ & & & $0.001^{*}$ \\
\hline Employed $\ddagger$ & $5354(70.4)$ & 724 (68.3) & $3521(79.5)$ & & $158(51.6)$ & $951(52.5)$ & \\
\hline Unemployed § & $486(6.4)$ & $169(15.9)$ & $260(5.9)$ & & $18(5.9)$ & $39(2.2)$ & \\
\hline Housewife $\dagger$ & $531(7.0)$ & - & - & & $76(24.8)$ & $455(25.1)$ & \\
\hline Retired $†$ & $190(2.5)$ & $10(1.0)$ & $130(2.9)$ & & $2(0.7)$ & $48(2.7)$ & \\
\hline Student & $934(12.3)$ & $123(11.6)$ & $450(10.2)$ & & $49(16.0)$ & $312(17.2)$ & \\
\hline Missing data & $110(1.4)$ & $34(3.2)$ & $67(1.5)$ & & $3(1.0)$ & $6(0.3)$ & \\
\hline \multicolumn{2}{|c|}{ Household SES cluster, n (\%) } & & & $<0.001^{*}$ & & & 0.202 \\
\hline Rural poor† & $43(0.6)$ & $6(0.5)$ & $27(0.6)$ & & $1(0.3)$ & $9(0.5)$ & \\
\hline Rural wealthy $\dagger$ & $683(9.0)$ & $76(7.2)$ & $436(9.8)$ & & $31(10.1)$ & $140(7.7)$ & \\
\hline Urban poor & $110(1.5)$ & $37(3.5)$ & $53(1.2)$ & & $5(1.7)$ & $15(0.8)$ & \\
\hline $\begin{array}{l}\text { Urban MC } \\
\text { homeowner }\end{array}$ & $906(11.9)$ & $145(13.7)$ & $560(12.7)$ & & $27(8.8)$ & $174(9.6)$ & \\
\hline $\begin{array}{l}\text { Urban MC } \\
\text { tenant }\end{array}$ & $4135(54.4)$ & $617(58.2)$ & $2409(54.4)$ & & $171(55.9)$ & $938(51.8)$ & \\
\hline Urban wealthy & $1468(19.3)$ & $143(13.5)$ & $801(18.1)$ & & 61 (19.9) & $463(25.6)$ & \\
\hline Missing data & $260(3.4)$ & $36(3.4)$ & $142(3.2)$ & & $10(3.3)$ & $72(4.0)$ & \\
\hline \multicolumn{2}{|l|}{ Alcohol use, n (\%) q } & & & $<0.001^{*}$ & & & $<0.001^{*}$ \\
\hline Yes & $817(10.7)$ & $210(19.8)$ & $490(11.1)$ & & $42(13.7)$ & $75(4.1)$ & \\
\hline No & 6077 (79.9) & $702(66.2)$ & 3521 (79.5) & & $251(82.0)$ & $1603(88.5)$ & \\
\hline Unknown & $711(9.4)$ & $148(14.0)$ & $417(9.4)$ & & $13(4.3)$ & $133(7.4)$ & \\
\hline
\end{tabular}

*Significant at the $\mathrm{p}<0.05$ level.

†Variable categories combined for inclusion in multivariable logistic regression models.

łIncludes self-employed, salaried worker and any applicable free-text responses.

§Includes unemployed (unable to work) and unemployed (able to work).

I"Did alcohol likely contribute to this injury?"

IPVRI, Interpersonal violence-related injury; MC, middle-class ; SES, socioeconomic status .

tenant and urban wealthy clusters. ${ }^{46}$ Similar associations between lower SES and IPVRI have been identified in household survey data from Sudan, ${ }^{30}$ South Africa ${ }^{29}$ and sub-Saharan Africa ${ }^{49}$ using the wealth index model and in hospital data from Ethiopia ${ }^{22}{ }^{23}$ and The Gambia ${ }^{19}$ using household income.

Though the EconomicClusters model does yield two rural SES clusters, we chose to combine them into a single 


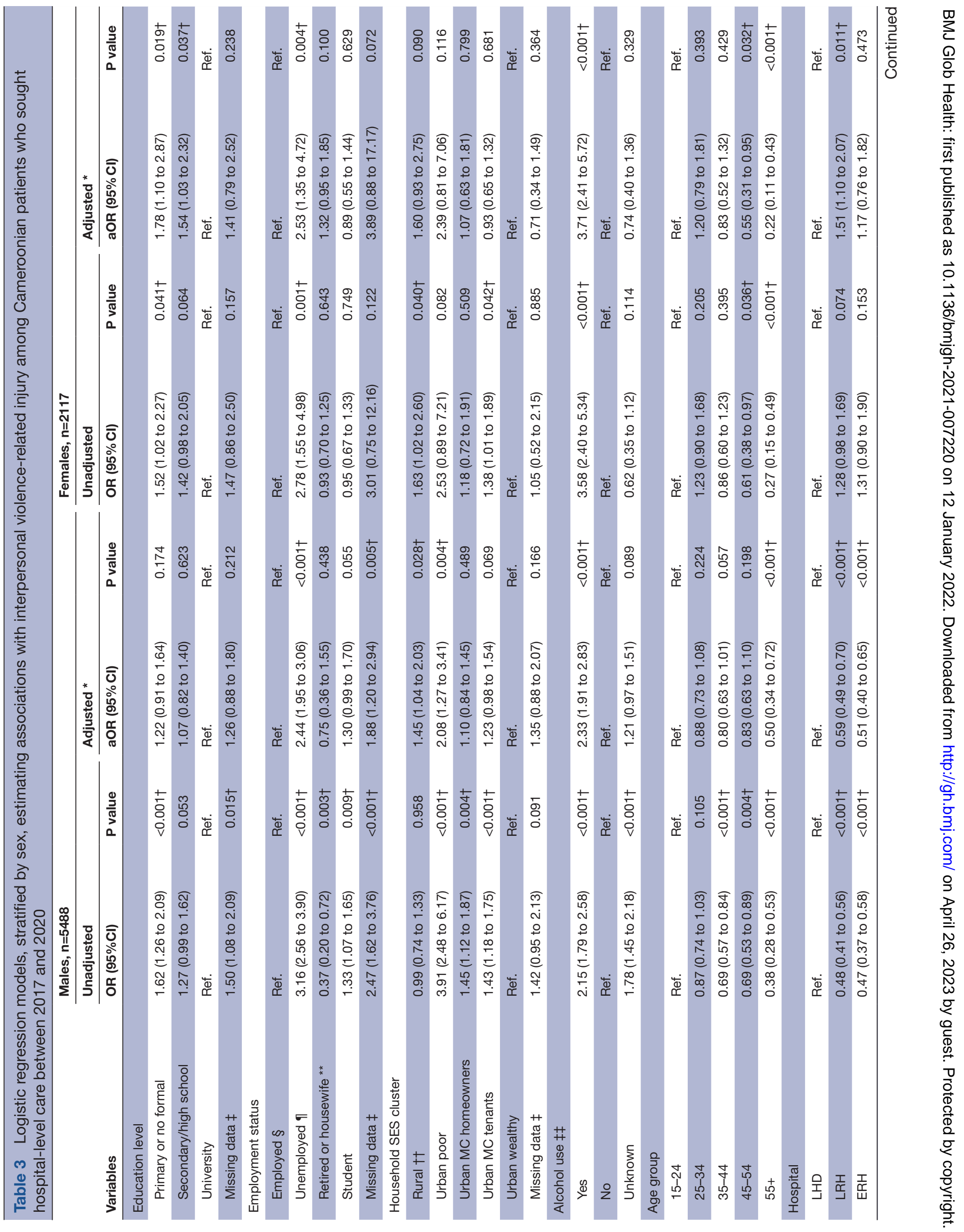




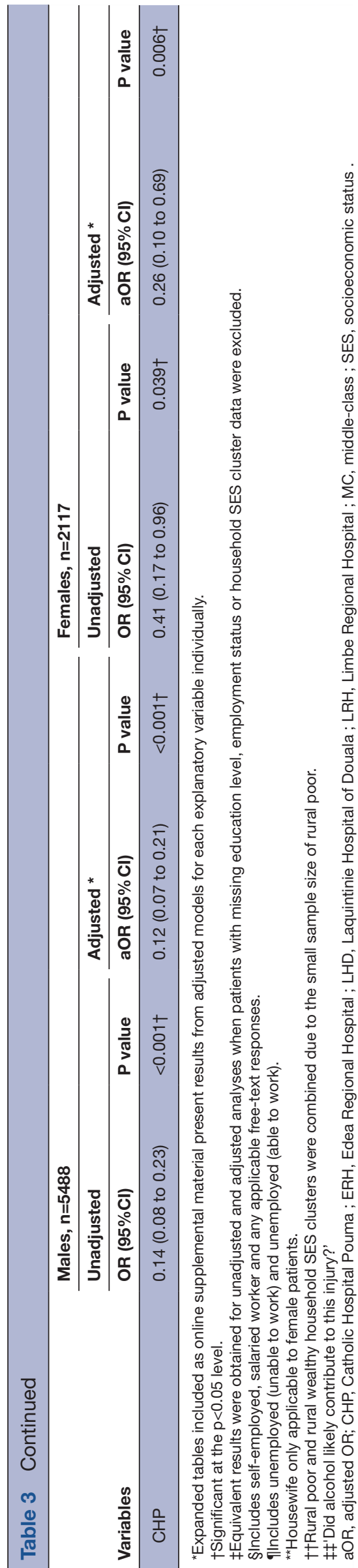

rural cluster due to a small sample of patients from rural households seeking care at these four urban or periurban hospitals. The rural poor and rural wealthy clusters comprised $26.0 \%$ and $26.6 \%$ of the 2011 DHS population, respectively, ${ }^{45}{ }^{46}$ but only $0.6 \%$ and $9.0 \%$ of our trauma registry sample. The over-representation of patients from higher-SES urban households in our trauma registry data has been described previously, and is due in part to the urban or peri-urban location of the four pilot hospitals as well as differences in care seeking behaviour among the lower-SES household clusters. ${ }^{38}$ Further research is warranted to better describe the burden of IPVRI among the rural population of Cameroon.

While not technically an SDH, ${ }^{11}{ }^{12}$ we chose to include alcohol use as a predictor of IPVRI due to its association with the SDH variables considered in this study ${ }^{147}$ and its known contribution to risk of IPVRI. ${ }^{13} 58$ We found very strong evidence to suggest that alcohol use is associated with increased risk of IPVRI among both male and female patients in Cameroon. Our findings are consistent with a number of other studies exploring risk of IPVRI in the region. ${ }^{171831}$ 59-62 The WHO collaborative study on alcohol and injuries also found that alcohol consumption was associated with greater odds of IVPRI compared with unintentional injuries, though the study did not include any sub-Saharan African countries. ${ }^{13}$ Reducing access to and the harmful use of alcohol is a key violence prevention strategy endorsed by the WHO. ${ }^{36364}$

While risk of IPVRI is the result of many inter-related societal, community, relationship and individual factors, several of the violence prevention strategies endorsed by the WHO specifically target the $\mathrm{SDH}$ explored in this study. ${ }^{363}$ Targeting these upstream risk factors for IPVRI can be approached at the population level through policy, or through interventions focused more directly on individuals or groups known to be at higher risk. ${ }^{164}$ Educational attainment initiatives are typically targeted toward children and adolescents, and could include academic enrichment programmes ${ }^{346364}$ or incentives to complete secondary education and seek a post-secondary education, ${ }^{3} 6364$ particularly for women. With regards to unemployment as a risk factor for violence, possible interventions include job creation programmes for those who are 'chronically unemployed' or vocational or lifeskills training for teenagers and young adults known to be involved in violence. ${ }^{3} 6364$ Violence prevention efforts targeting SES include policy to deconcentrate poverty, reduce housing density and alleviate economic inequality. ${ }^{3} 63 \quad 64$ Additional upstream interventions targeting low SES communities have included conditional cash transfer programmes or urban upgrading, ${ }^{6566}$ while more individual-oriented violence prevention efforts in LMICs include the Cure Violence model in Honduras, ${ }^{67}$ Sanando Heridas in El Salvador ${ }^{68}$ or the Jamaica Peace Management Initiative. ${ }^{69}$ Of note, the Sanando Heridas programme in El Salvador is based on the hospital-based violence intervention programme (HVIP) framework, which is a model of the integration of social care into 
medical care and has been shown to be an effective violence prevention strategy in HICs. ${ }^{68} 70$ HVIPs use the time spent in the ED or hospital as an opportunity to connect victims of IPVRI with resources and/or referral services to address the risk factors discussed in this study, such as low educational attainment, unemployment or harmful alcohol use, among others. Hospital-based programmes such as these are in line with the WHO recommendation that its member states work to incorporate violence prevention efforts into the healthcare setting, ${ }^{2}{ }^{72}$ but feasibility and effectiveness of HVIPs has yet to be established in an LMIC setting.

It is important to address the predominance of male patients in our study sample. Prior research using trauma registry data in Cameroon as well as similar studies using hospital-based data from the region have found a similarly high risk of IPVRI among male compared with female patients. ${ }^{1722} 27373940$ In contrast, the 2018 DHS data for Cameroon found that a higher percentage of women compared with men $(18.4 \%$ vs $14.1 \%)$ reported experiencing physical violence in the previous year. ${ }^{34}$ Violence against women is known to be particularly prone to under-representation in official statistics and hospitalbased data, due in part to women being less likely to seek care for non-fatal IPVRIs compared with men, especially when the perpetrator is an intimate partner or spouse. ${ }^{2}$ Even women that do seek care for injuries inflicted by an intimate partner may be misclassified as having unintentional injury. ${ }^{2} \mathrm{~A}$ large percentage of female patients in our study reported the perpetrator of IPVRI to be a partner or ex-partner, but this does not negate the possibility that other injuries due to intimate partner violence could have been misclassified as unintentional or excluded due to missing intention of injury.

\section{Limitations}

Our study has several limitations to discuss. First, hospital data are known to incompletely capture injury data and likely under-report all injuries, both intentional and unintentional, compared with the prevalence in the community. Additionally, as discussed above with regard to sex and household SES, use of hospital-based injury data are prone to selection bias, suggesting the need to explore the association between SDH and IPVRI using community-based data as well. Our control group was comprised of patients presenting to a hospital with an unintentional injury and is likely demographically different from a group of uninjured persons. However, as mentioned above, this would likely result in underestimation of associations between IPVRI and our predictors. Additionally, since intention of injury was self-reported, it is possible some patients with IPVRI may have been misclassified with the unintentional injury group or excluded due to missing intention data, particularly for victims of intimate partner violence or youth injured by their parents. Key data were missing for employment, education and SES, particularly for those who died in the ED, which limited our ability to explore associations between SDH and clinical outcomes. Our measure of employment status did not consider job stability of those who were reportedly employed, nor did our categorisation of 'employed' capture the full diversity of types of employment in sub-Saharan Africa. ${ }^{34}$ Lastly, while the research assistants involved with the collection of trauma registry data have been trained in the ethics of human subjects research, they have not received training specific to the safety and ethics of collecting data on violence against women. ${ }^{48}$ Despite these limitations, we believe these data offer an important contribution to the limited body of literature describing risk and protective factors as they relate to IPVRI in LMICs.

\section{CONCLUSIONS}

IPVRI remains a leading cause of global injury and death, but data to inform prevention strategies remain limited in LMICs, particularly in sub-Saharan Africa. Results from this analysis are suggestive of higher education, employment, higher household SES and reducing harmful use of alcohol as protective factors against IPVRI in Cameroon. More data are needed to further characterise these associations among the rural population of Cameroon, and future studies should explore setting-appropriate interventions to address risk factors for IPVRI in Cameroon.

\section{Author affiliations}

${ }^{1}$ Program for the Advancement of Surgical Equity (PASE), Department of Surgery, University of California Los Angeles, Los Angeles, California, USA

${ }^{2}$ Boston University School of Medicine, Boston, Massachusetts, USA

${ }^{3}$ Littoral Regional Delegation, Cameroon Ministry of Public Health, Douala, Cameroon

${ }^{4}$ Division of Biostatistics, University of California Berkeley School of Public Health Berkeley, California, USA

${ }^{5}$ Department of Trauma and Acute Care Surgery, University of Pittsburgh Medical Center, Pittsburgh, Pennsylvania, USA

${ }^{6}$ Department of Disease Epidemic and Pandemic Control, Cameroon Ministry of Public Health, Yaoundé, Cameroon

${ }^{7}$ Hospital Administration, Limbe Regional Hospital, Limbe, Southwest Region, Cameroon

${ }^{8}$ Hospital Administration, Hopital Laquintinie de Duoala, Duoala, Cameroon ${ }^{9}$ Hospital Administration, Catholic Hospital of Pouma, Pouma, Cameroon

${ }^{10} \mathrm{Hospital}$ Administration, Edea Regional Hospital, Edea, Cameroon

${ }^{11}$ Department of Surgery and Obs/Gyn, University of Buea Faculty of Health Sciences, Buea, Cameroon

Twitter Kevin J Blair @KJBlairMD, Michael de Virgilio @m_devirgilio, Lauren Eyler Dang @LE_Eyler, Rochelle A Dicker @rochelleami9, Alain Chichom-Mefire @chichomefire and Catherine Juillard @cjuillard

Acknowledgements This work would not have been possible without the dedication and effort of the Cameroonian trauma registry staff at each participating hospital, who collect and compile data from each injured patient. Moreover, the success of the Cameroon National Trauma Registry is a result of the commitment from the Cameroon Ministry of Public Health and leadership at each participating hospital to the importance of data to guide both prevention and quality improvement interventions in the country. Prior presentation: These data were presented at the 5th World Trauma Congress on 15 February 2021

Contributors KJB, MdV, FND-D, LED, SAC, MC, RO, RAD, AC-M and CJ were involved with idea generation and study planning. FND-D, MM, MC, RO, AME, TK, RLN, DNN, J-GT and AC-M were involved with trauma registry data collection and organisation. KJB, LED and AEH conducted data analysis. KJB, MdV, FND-D, LED, SAC, MC, R0, AEH, RAD, AC-M and CJ interpreted and contextualised the 
results. KJB and MdV drafted the initial manuscript. All authors were involved with the editing and revisions of the manuscript, and all authors contributed to final approval to the submitted version. $\mathrm{KJB}$ is the guarantor and accepts full responsibility for the finished work and/or the conduct of the study, had access to the data, and controlled the decision to publish.

Funding This research was supported by the H. and H. Lee Surgical Research Scholars Programme through the University of California, Los Angeles.

Competing interests None declared.

\section{Patient consent for publication Not applicable.}

Ethics approval Approval to conduct this study was granted by the University of California, Los Angeles (IRB\#19-000086) and University of California, San Francisco (IRB\#13-12535) institutional review boards, as well as the Cameroon National Ethics Committee of the Division of Health Operations Research of the Ministry of Public Health (No2014/09/496/CE/CNERSH/SP). Participants gave informed consent to participate in the study before taking part.

Provenance and peer review Not commissioned; externally peer reviewed.

Data availability statement Data are not publicly available but may be requested from the authors on reasonable request.

Supplemental material This content has been supplied by the author(s). It has not been vetted by BMJ Publishing Group Limited (BMJ) and may not have been peer-reviewed. Any opinions or recommendations discussed are solely those of the author(s) and are not endorsed by BMJ. BMJ disclaims all liability and responsibility arising from any reliance placed on the content. Where the content includes any translated material, BMJ does not warrant the accuracy and reliability of the translations (including but not limited to local regulations, clinical guidelines, terminology, drug names and drug dosages), and is not responsible for any error and/or omissions arising from translation and adaptation or otherwise.

Open access This is an open access article distributed in accordance with the Creative Commons Attribution Non Commercial (CC BY-NC 4.0) license, which permits others to distribute, remix, adapt, build upon this work non-commercially, and license their derivative works on different terms, provided the original work is properly cited, appropriate credit is given, any changes made indicated, and the use is non-commercial. See: http://creativecommons.org/licenses/by-nc/4.0/.

\section{ORCID iDs}

Kevin J Blair http://orcid.org/0000-0003-1390-2508

Lauren Eyler Dang http://orcid.org/0000-0002-2967-0855

Alain Chichom-Mefire http://orcid.org/0000-0001-7230-567X

\section{REFERENCES}

1 Mercy JA, Hillis SD, Butchart A. Interpersonal Violence: Global Impact and Paths to Prevention. In: In: disease control priorities. Third ed. Washington, DC: The World Bank, 2017.

2 WHO. Global status report on violence prevention. Geneva, Switzerland: WHO, 2014.

3 WHO. Preventing violence: a guide to implementing the recommendations of the world report on violence and health. Geneva, Switzerland: WHO, 2004.

4 Mikton CR, Tanaka M, Tomlinson M, et al. Global research priorities for interpersonal violence prevention: a modified Delphi study. Bull World Health Organ 2017;95:36-48.

5 Krug EG, Mercy JA, Dahlberg LL, et al. World report on violence and health. Geneva: World Health Organization, 2002: 360. 1083-8.

6 The Lancet global health metrics. interpersonal Violence-Level 3 cause. The Lancet 2020.

7 World Health Assembly. Prevention of violence: a public health priority (WHA49.25) [press release], 1996.

8 World Health Assembly. Implementing the recommendations of the world report on violence and heealth (WHA56.24), 2003.

9 World Health Assembly. Strengthening the role of the health system in addressing violence, in particular against women and girls, and against children (WHA67.15) [press release]. 2014.

10 World Health Assembly. WHO global plan of action to stregthen the role of the health system within a national multisectorial response to address interpersonal violence, in particular against women and girls, and against children (WHA69.5) [press release], 2016.

11 WHO. Social determinants of health. Available: https://www.who.int/ health-topics/social-determinants-of-health\#tab=tab_1

12 Moor I, Spallek J, Richter M. Explaining socioeconomic inequalities in self-rated health: a systematic review of the relative contribution of material, psychosocial and behavioural factors. J Epidemiol Community Health 2017;71:565-75.

13 Borges Get al. Multicentre study of acute alcohol use and non-fatal injuries: data from the who Collaborative study on alcohol and injuries. Bull World Health Organ 2006;84:453-60.

14 Probst C, Lange S, Kilian C, et al. The dose-response relationship between socioeconomic deprivation and alcohol-attributable mortality risk - a systematic review and meta-analysis. BMC Med 2021;19:268.

15 Our world in data. Available: https://ourworldindata.org/ [Accessed 19 Jan 2021].

16 WHO. World report on violence and health. Geneva, Switzerland, 2002.

17 Purcell LN, Kayange L, Gallaher J, et al. The inter-relationship between employment status and interpersonal violence in Malawi: a trauma center experience. World J Surg 2020;44:2927-34.

18 Leeper S, Lahri Sa'ad, Myers J, et al. Assault-injured youth in the emergency centres of Khayelitsha, South Africa: Baseline characteristics \& opportunities for intervention. Injury 2019;50:2220-7.

19 Bass P, Yu W-Y, Sanyang E, et al. Risk factors for recurrent injuries from physical violence among African men in the Gambia. $J$ Community Health 2019;44:596-604.

20 Bass $\mathrm{P}$, Sanyang E, Lin M-R. Risk factors for violent injuries and their severity among men in the Gambia. Am J Mens Health 2018;12:2116-27.

21 Njeru EK, Mutiso VM, Saidi H. Firearm injuries at selected hospitals in Kenya. The Annals of African Surgery 2008;3:3-9.

22 Tadesse BT, Dachew BA, Bifftu BB, et al. High incidence of interpersonal violence in Northwest Ethiopia: a cross-sectional study. Int Emerg Nurs 2015;23:213-7.

23 Tadesse B, Tekilu S, Nega B. Pattern of injury and associated variables as seen in the emergency department at Tikur Anbessa specialized referral Hospital, Addis Ababa, Ethiopia. East Cent Afr J Surg 2014;19:73-82

24 Chalya PL, Gilyoma JM. The burden of intentional injuries in Mwanza City, north-western Tanzania: a tertiary hospital survey. Tanzan J Health Res 2012;14

25 Okulate GT. Interpersonal violence cases reported to the police: a Nigerian study. J Interpers Violence 2005;20:1598-610.

26 Kiser M, Escamilla V, Samuel J, et al. Sex differences in interpersonal violence in Malawi: analysis of a hospital-based trauma registry. World J Surg 2013;37:2972-8.

27 Schuurman N, Cinnamon J, Walker BB, et al. Intentional injury and violence in Cape town, South Africa: an epidemiological analysis of trauma admissions data. Glob Health Action 2015;8:27016.

28 Gardner A, Forson PK, Oduro G, et al. Harmful alcohol use among injured adult patients presenting to a Ghanaian emergency department. Inj Prev 2017;23:190-4.

29 Doolan K, Ehrlich R, Myer L. Experience of violence and socioeconomic position in South Africa: a national study. PLoS One 2007;2:e1290.

30 Abdalla S. Sudan household health survey national management T. patterns of vulnerability to non-fatal injuries in Sudan: initial evidence from a national cross-sectional survey. Inj Prev 2014;20:310-6.

31 Gathecha GK, Ngaruiya C, Mwai W, et al. Prevalence and predictors of injuries in Kenya: findings from the National steps survey. BMC Public Health 2018;18:1222.

32 Otieno G, Marinda E, Bärnighausen T, et al. High rates of homicide in a rural South African population (2000-2008): findings from a population-based cohort study. Popul Health Metr 2015;13.

33 Fry L. Factors which predict violence victimization in Uganda. Pan Afr Med J 2014;19:335.

34 Institut National de la Statistique (INS) and ICF. Enquête Démographique et de Santé Du Cameroun 2018. Yaoundé, Cameroun and Rockville, Maryland, USA: INS and ICF, 2020. https://dhsprogram.com/methodology/survey/survey-display-511. cfm

35 ClA. The World Factbook-Cameroon, 2020. Available: https://www. cia.gov/library/publications/the-world-factbook/geos/cm.html

36 Chichom-Mefire A, Nwanna-Nzewunwa OC, Siysi VV, et al. Key findings from a prospective trauma registry at a regional hospital in Southwest Cameroon. PLoS One 2017;12:e0180784.

37 Nwanna-Nzewunwa OC, Christie SA, Carvalho M. Analysis of a national trauma registry in Cameroon: implications for prehospita care Stregthening. Panam J Trauma Crit Care Emerg Surg 2018;7:133-42.

38 Kacker S, Bishai D, Mballa GAE, et al. Socioeconomic correlates of trauma: an analysis of emergency ward patients in Yaoundé, Cameroon. Injury 2016;47:658-64. 
39 Juillard CJ, Stevens KA, Monono ME, et al. Analysis of prospective trauma registry data in Francophone Africa: a pilot study from Cameroon. World J Surg 2014;38:2534-42.

40 Juillard C, Etoundi Mballa GA, Bilounga Ndongo C, et al. Patterns of injury and violence in Yaoundé Cameroon: an analysis of hospital data. World J Surg 2011;35:1-8.

41 Harris PA, Taylor R, Thielke R, et al. Research electronic data capture (REDCap) - A metadata-driven methodology and workflow process for providing translational research informatics support. J Biomed Inform 2009;42:377-81.

42 Harris PA, Taylor R, Minor BL, et al. The REDCap Consortium: building an international community of software platform partners. $J$ Biomed Inform 2019;95:103208.

43 WHO. Global status report on road safety 2018, 2018. Available: https://www.who.int/news-room/fact-sheets/detail/road-trafficinjuries

44 Baker SP, O'Neill B, Haddon W, et al. The injury severity score: a method for describing patients with multiple injuries and evaluating emergency care. Journal of Trauma 1974;14:187-96.

45 Eyler L, Hubbard A, Juillard C. Assessment of economic status in trauma registries: a new algorithm for generating population-specific clustering-based models of economic status for time-constrained low-resource settings. Int $J$ Med Inform 2016;94:49-58.

46 Eyler L, Hubbard A, Juillard C. Optimization and validation of the EconomicClusters model for facilitating global health disparities research: examples from Cameroon and Ghana. PLoS One 2019;14:e0217197.

47 Stata LLC. Stata statistical software: release 16. College Station, TX, 2019

48 WHO. Putting women first: ethical and safety recommendations for research on domestic violence against women. Geneva, Switzerland: WHO, 2001. https://www.who.int/gender/violence/womenfirtseng. pdf

49 Ahinkorah BO, Dickson KS, Seidu A-A. Women decision-making capacity and intimate partner violence among women in subSaharan Africa. Arch Public Health 2018;76.

50 Semahegn A, Mengistie B. Domestic violence against women and associated factors in Ethiopia; systematic review. Reprod Health 2015;12:78

51 Kibusi SM, Ohnishi M, Outwater A, et al. Sociocultural factors that reduce risks of homicide in Dar es Salaam: a case control study. Inj Prev 2013;19:320-5.

52 Arroyave I, Burdorf A, Cardona D, et al. Socioeconomic inequalities in premature mortality in Colombia, 1998-2007: the double burden of non-communicable diseases and injuries. Prev Med 2014:64:41-7.

53 Dare AJ, Irving H, Guerrero-López CM, et al. Geospatial, racial, and educational variation in firearm mortality in the USA, Mexico, Brazil, and Colombia, 1990-2015: a comparative analysis of vital statistics data. The Lancet Public Health 2019;4:e281-90.

54 Rutstein SO, Johnson K. The DHS wealth index. Maryland, USA: ORC Macro, 2004.

55 Myer L, Ehrlich RI, Susser ES. Social epidemiology in South Africa. Epidemiol Rev 2004;26:112-23.
56 Gallo V, Mackenbach JP, Ezzati M, et al. Social inequalities and mortality in Europe - results from a large multi-National cohort. PLoS One 2012;7:e39013.

57 Grittner U, Kuntsche S, Gmel G, et al. Alcohol consumption and social inequality at the individual and country levels - results from an international study. Eur J Public Health 2013;23:332-9.

58 Taylor B, Irving HM, Kanteres F, et al. The more you drink, the harder you fall: a systematic review and meta-analysis of how acute alcohol consumption and injury or collision risk increase together. Drug Alcohol Depend 2010;110:108-16.

59 Plüddemann A, Parry C, Donson $\mathrm{H}$, et al. Alcohol use and trauma in Cape town, Durban and port Elizabeth, South Africa: 1999-2001. Inj Control Saf Promot 2004;11:265-7.

60 Nicol A, Knowlton LM, Schuurman N. Trauma surveillance in Cape town, South Africa: an analysis of 9236 consecutive trauma center admissions. JAMA Surg 2014;149:549-56.

61 Rubanzana W, Ntaganira J, Freeman MD, et al. Risk factors for homicide victimization in post-genocide Rwanda: a population -based case- control study. BMC Public Health 2015;15:809.

62 Odhiambo FO, Beynon CM, Ogwang S, et al. Trauma-related mortality among adults in rural Western Kenya: characterising deaths using data from a health and demographic surveillance system. PLoS One 2013;8:e79840.

63 WHO. Preventing youth violence: an overview of the evidence. Geneva, Switzerland, 2015.

64 Matzopoulos R, Bowman B, Mathews S, et al. Applying upstream interventions for interpersonal violence prevention: an uphill struggle in low- to middle-income contexts. Health Policy 2010;97:62-70.

65 Machado DB, Rodrigues LC, Rasella D, et al. Conditional cash transfer programme: impact on homicide rates and hospitalisations from violence in Brazil. PLoS One 2018;13:e0208925.

66 Matzopoulos R, Bloch K, Lloyd S, et al. Urban upgrading and levels of interpersonal violence in Cape town, South Africa: the violence prevention through urban upgrading programme. Soc Sci Med 2020;255:112978.

67 Ransford C, Decker RB, Cruz GM, et al. El modelo cure violence: reducción de la violencia en San Pedro Sula (Honduras). Revista CIDOB d'Afers Internacionals 2017;116:179-206.

68 Sanando Heridas Informe final: Evaluación de Impacto Y Evidencia Cualitativa, 2019Glasswing international. Available: https:// glasswing.org/es/wp-content/uploads/2019/12/ESSanando-HeridasINFORME-FINAL-1.pdf

69 Ward E, McGaw K, Hutchinson D, et al. Assessing the costeffectiveness of the peace management initiative as an intervention to reduce the homicide rate in a community in Kingston, Jamaica. Int J Public Health 2018;63:987-92.

70 Juillard C, Cooperman L, Allen I. A decade of hospital-based violence intervention: benefits and shortcomings. J Trauma Acute Care Surg 2016;81:1156-61.

71 Dicker R, Gaines B, Bonne S. Violence intervention programs: a primer for developing a comprehensive program for trauma centers. Chicago, IL: American College of Surgeons, 2017.

72 WHO. Global plan of action to strengthen the role of the health system within a national multisectoral response to address interpersonal violence, in particular against women and girls, and against children. Geneva, Switzerland: WHO, 2016. 